\title{
Microstructure, Elastic and Inelastic Properties of Partially Graphitized Biomorphic Carbons
}

\author{
T. S. Orlova ${ }^{a, b}, *$, B. K. Kardashev ${ }^{a}$, B. I. Smirnov ${ }^{a, * *}$, A. Gutierrez-Pardo ${ }^{c}$, \\ J. Ramirez-Rico ${ }^{c}$, and J. Martinez-Fernandez ${ }^{c}$ \\ ${ }^{a}$ Ioffe Physical-Technical Institute, Russian Academy of Sciences, Politekhnicheskaya ul. 26, St. Petersburg, 194021 Russia \\ *e-mail: orlova.t@mail.ioffe.ru \\ **e-mail:smir.bi@mail.ioffe.ru \\ ${ }^{b}$ National Research University of Information Technologies, Mechanics and Optics, \\ Kronverkskii pr. 49, St. Petersburg, 197101 Russia \\ ${ }^{c}$ Departamento de Fisica de la Materia Condensada-Instituto de Ciencia de Materiales de Sevilla (ICMSE), \\ Universidad de Sevilla, Apartado de Correos 1065, Sevilla, ES41080 Spain
}

Received September 15, 2014

\begin{abstract}
The microstructural characteristics and amplitude dependences of the Young's modulus $E$ and internal friction (logarithmic decrement $\delta$ ) of biocarbon matrices prepared by beech wood carbonization at temperatures $T_{\text {carb }}=850-1600^{\circ} \mathrm{C}$ in the presence of a nickel-containing catalyst have been studied. Using $\mathrm{X}$-ray diffraction and electron microscopy, it has been shown that the use of a nickel catalyst during carbonization results in a partial graphitization of biocarbons at $T_{\text {carb }} \geq 1000^{\circ} \mathrm{C}$ : the graphite phase is formed as 50 to $100-\mathrm{nm}$ globules at $T_{\text {carb }}=1000^{\circ} \mathrm{C}$ and as 0.5 - to $3.0-\mu \mathrm{m}$ globules at $T_{\text {carb }}=1600^{\circ} \mathrm{C}$. It has been found that the measured dependences $E\left(T_{\text {carb }}\right)$ and $\delta\left(T_{\text {carb }}\right)$ contain three characteristic ranges of variations in the Young's modulus and logarithmic decrement with a change in the carbonization temperature: $E$ increases and $\delta$ decreases in the ranges $T_{\text {carb }}<1000^{\circ} \mathrm{C}$ and $T_{\text {carb }}>1300^{\circ} \mathrm{C}$; in the range $1000<T_{\text {carb }}<1300^{\circ} \mathrm{C}, E$ sharply decreases and $\delta$ increases. The observed behavior of $E\left(T_{\text {carb }}\right)$ and $\delta\left(T_{\text {carb }}\right)$ for biocarbons carbonized in the presence of nickel correlates with the evolution of their microstructure. The largest values of $E$ are obtained for samples with $T_{\text {carb }}=1000$ and $1600^{\circ} \mathrm{C}$. However, the samples with $T_{\text {carb }}=1600^{\circ} \mathrm{C}$ exhibit a higher susceptibility to microplasticity due to the presence of a globular graphite phase that is significantly larger in size and total volume.
\end{abstract}

DOI: $10.1134 / \mathrm{S} 106378341503018 \mathrm{X}$

\section{INTRODUCTION}

Biomorphic carbon matrices produced by carbonization of natural wood or wood fiber-boards are promising materials for various practical applications. Being characterized by natural open porosity (to $75 \%$ ), they can be used as matrices for developing new composites such as bioC-metal, bioC-polymer, and for producing light porous biomorphic ceramics $\mathrm{SiC}$ and composites $\mathrm{SiC} / \mathrm{Si}$ on their basis [1-3].

Different porous carbons are conventionally used as materials for electrodes, which is caused by their chemical resistance to different electrolytes, wide operating temperature ranges, and simple fabrication of electrodes. The use of biocarbon materials as electrodes for energy accumulator systems (electrochemical capacitors) seems promising, since they have large surface areas, high conductivity, interconnected porous structure, controllable pore sizes appropriate for electrolyte ions, and electrochemically stable surfaces $[4,5]$. They do not require binding materials for producing electrodes; in this case, the entire carbon skeleton is involved in electrode operation.
In recent years, particular interest is attracted by graphitized biocarbon matrices produced also by natural wood carbonization only in the presence of transition metal catalysts [6-8]. Due to the retention of the natural porosity inherent to natural wood and high heat and electrical conductivity of graphite, the fabrication of graphitized biocarbon matrices is of great practical interest. Conventional pyrolysis (carbonization) of wood does not allow production of graphitized carbon even as the treatment temperature is increased to $3000^{\circ} \mathrm{C}[1,9]$. In this case, the so-called turbostatic carbon is formed, which consists of misoriented carbon layers spaced by distances exceeding the interplane distance $(3.354 \AA$ ) of perfect graphite [10]. To improve ordering in the structure of non-graphitized carbons, transition metal catalysts based on iron, cobalt, nickel, and copper are used, whose use results in the formation of graphitized carbon even at $T_{\text {carb }}>$ $500^{\circ} \mathrm{C}[11-14]$. The graphitization of carbons using transition metal catalysts well proved in the case of thin films, aerogels, and cellulose powders. Only few in number studies are devoted to graphitization of bulk 
carbons carbonized from natural wood [6-8]. In [6], using liquid catalysts based on nickel in wood carbonization, porous carbons with a graphitized phase content typical of carbons produced from pitch-based graphite were produced retaining the biocarbon porous structure. These biomorphic graphitized carbons showed a significantly higher thermal conductivity in comparison with ordinary quasi-amorphous biocarbons [7]. However, elastic, microplastic, and strength properties of graphitized biocarbons were not studied.

In the present work, using a similar carbonization method in the presence of catalyst with varied carbonization temperature $T_{\text {carb }}$, beech wood biocarbons were produced, and the dependences of the Young's modulus and internal friction on $T_{\text {carb }}$ in comparison with their microstructural features were studied for the first time. These data are compared with similar dependences we previously obtained in [15] for biocarbons carbonized under the same conditions, but in the absence of catalyst.

\section{SAMPLE PREPARATION AND EXPERIMENTAL TECHNIQUE}

The samples of biocarbon produced by beech wood carbonization at different temperatures $T_{\text {carb }}=600-$ $1600^{\circ} \mathrm{C}$ were studied in the absence and in the presence of Ni-containing catalyst. As a precursor, wood pieces $75 \times 15 \times 15 \mathrm{~mm}$ in size were used, which were preliminarily dried in a furnace to eliminate residual water from pores to prevent cracking during subsequent pyrolysis. A saturated solution of nickel nitrate $\left(\mathrm{Ni}\left(\mathrm{NO}_{3}\right)_{2} \cdot 6 \mathrm{H}_{2} \mathrm{O}\right)$ in isopropyl alcohol was used as a catalyst, into which samples were placed for filling their pores. To provide complete filling of the entire pore space by solution, air from pores was preliminarily pumped out by placing the sample to a vacuum chamber. The samples were kept in the solution for a certain time, and then were dried in air at room temperature for $24 \mathrm{~h}$ followed by additional drying at $80^{\circ} \mathrm{C}$ until complete drying which was controlled by a change in the precursor weight. The pyrolysis process was performed in an inert gas (99.999\% nitrogen) flow. The heating rate was $1{ }^{\circ} \mathrm{C} / \mathrm{min}$ to $500^{\circ} \mathrm{C}$, then $5^{\circ} \mathrm{C} / \mathrm{min}$ to $T_{\text {carb }}(600,850,1000,1150,1300,1400$, 1500 , and $1600^{\circ} \mathrm{C}$ ) at which the sample was kept for $30 \mathrm{~min}$ and then was cooled with a rate of $5^{\circ} \mathrm{C} / \mathrm{min}$. Then Ni catalyst particles were removed by washing the samples in concentrated $\mathrm{HCl}$ acid (37\%, Panreac) for $2 \mathrm{~h}$ followed by washing in deionized water with neutral $\mathrm{pH}$ and drying in a furnace. This method for producing graphitized biocarbons is described in detail in [8]. In what follows, we present the results for graphitized samples after removing residual nickel from them, except for specially mentioned cases. For comparison, some samples were prepared at the same heat treatment parameters, but in the absence of catalyst. In what follows, we denote beech biocarbon sam- ples carbonized at certain $T_{\text {carb }}$ after treatment by a Nicontaining catalyst by BE-C- $T_{\text {carb }}(\mathrm{Ni})$; i.e., BE-C$850(\mathrm{Ni})$ is biocarbon produced by beech wood carbonization at $T_{\text {carb }}=850^{\circ} \mathrm{C}$ in the presence of Ni catalyst. Accordingly, samples carbonized without nickel are denoted by BE-C-600, BE-C-850, and so on.

The structure of carbonized samples was studied by $\mathrm{X}$-ray diffraction and scanning electron microscopy (SEM) methods.

Samples for acoustic studies were prepared as rods $\sim 20 \mathrm{~mm}$ long with approximately square cross section $\sim 16 \mathrm{~mm}^{2}$ in area. Samples oriented by the long side along growth fibers of primary wood we studied. The Young's modulus $E$ and ultrasonic vibration decrement $\delta$ were measured using the composite vibrator method. Longitudinal resonant vibrations were excited in samples at a frequency of $\sim 100 \mathrm{kHz}$. The Young's modulus $E$ and ultrasonic vibration decrement $\delta$ were measured as functions of the acoustic vibration amplitude. The range of vibrational strain amplitudes $\varepsilon$ was from $\sim 10^{-7}$ to $2 \times 10^{-4}$. The method is described in detail in [16]. To measure the amplitude dependences $E(\varepsilon)$ and $\delta(\varepsilon)$, the acoustic system (sample and quartz converter) was placed into a vacuum chamber, from which air was pumped out to $\sim 10^{-3} \mathrm{mmHg}$. Then the amplitude dependences of the Young's modulus $E$ and decrement $\delta$ were measured at room temperature.

\section{EXPERIMENTAL RESULTS AND DISCUSSION}

\subsection{Structural Characterization of Samples}

First of all, the effect of catalytic pyrolysis (carbonization) on changes in the crystal structure and the degree of residual disordering was measured by X-diffraction analysis methods. Figure 1 shows the example of X-ray diffraction patterns of biocarbon samples carbonized at different temperatures using a nickel-containing catalyst. We can see that the use of catalyst at $T_{\text {carb }} \geq 1000^{\circ} \mathrm{C}$ results in the formation of a graphitized phase, as suggested by the appearance of the strong (002) peak at $2 \theta=26.6^{\circ}$ in the X-ray pattern (Fig. 1). At lower carbonization temperatures, the use of catalyst was inefficient for forming an appreciable graphite phase fraction.

The degree of ordering of the biocarbon structure was studied by Raman spectroscopy in [8]. These data also show a substantial increase in the degree of graphitization in the samples treated by Ni-catalysts, in comparison with untreated samples with increased $T_{\text {carb }} \geq 1000^{\circ} \mathrm{C}$ [8].

The use of catalyst had no effect on the macroporous structure of biocarbon samples: at all carbonization temperatures, it remained similar and was characterized by the presence of pores of small (3-7 $\mu \mathrm{m})$ and large $(22-38 \mu \mathrm{m})$ diameters, oriented 


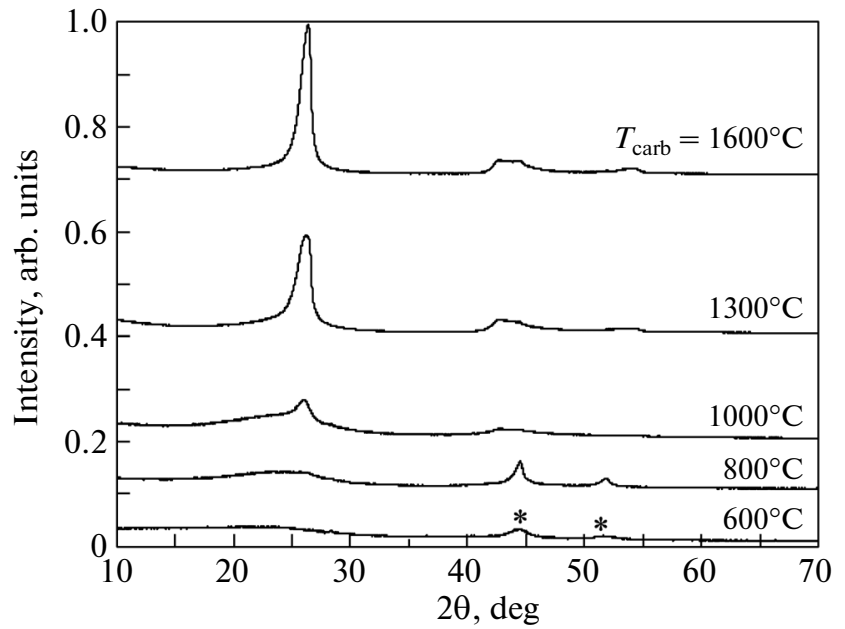

Fig. 1. X-ray diffraction patterns of biocarbon samples carbonized at different temperatures in the presence of $\mathrm{Ni}$ catalyst. Asterisks indicate the peaks corresponding to residual $\mathrm{Ni}$ after sample etching in $\mathrm{HCl}$.

along the wood growth. The total volume of such microscopic pores in the samples was $65 \pm 5 \%$ [6]. Measurements of the density of the carbon skeletons themselves using a helium picnometer [8] indicate the formation of additional nanoporosity in biocarbons with $T_{\text {carb }}>1000^{\circ} \mathrm{C}$ comparable to that of BE-C samples [15].

The biocarbon microstructure was studied by scanning electron microscopy. Electron microscopy images of the BE-C(Ni) sample structure with $T_{\text {carb }}=1000$ and $1600^{\circ} \mathrm{C}$ are shown in Figs. $2 \mathrm{a}$ and $2 \mathrm{~b}$, respectively. At $T_{\text {carb }}=1000^{\circ} \mathrm{C}$, a graphite phase is formed near $\mathrm{Ni}$ particles (Fig. 2a). Lower carbonization temperatures were inefficient for graphitization. The fine structure of the nucleating graphite phase was studied in detail in [8] by transmission electron microscopy. It was shown that the nucleating phase represents graphene layers growing around Ni particles and forming hollow nanospheres 50-100 nm in size after nickel removal. In bioC-1600(Ni) samples, large graphite globules (grains) $0.5-3.0 \mu \mathrm{m}$ in size are formed (Fig. 2b). The fraction of the formed graphite phase in samples with $T_{\text {carb }}=1000^{\circ} \mathrm{C}$ is small (Fig. 2a), whereas it occupies a significant part of the sample volume in samples with $T_{\text {carb }}=1600^{\circ} \mathrm{C}$ (Fig. $\left.2 \mathrm{~b}\right)$. It should be noted that graphite phase globules larger than $1 \mu \mathrm{m}$ were formed only at carbonization temperatures exceeding the nickel melting temperature of $\sim 1450^{\circ} \mathrm{C}$.

\subsection{Elastic and Inelastic Properties}

Figure 3 shows the dependences of the modulus $E$ and decrement $\delta$ on the carbonization temperature, measured in vacuum after pumping air for bioC(Ni) biocarbon matrices produced by beech carbonization in the presence of Ni-containing catalyst (curves 1 ). In
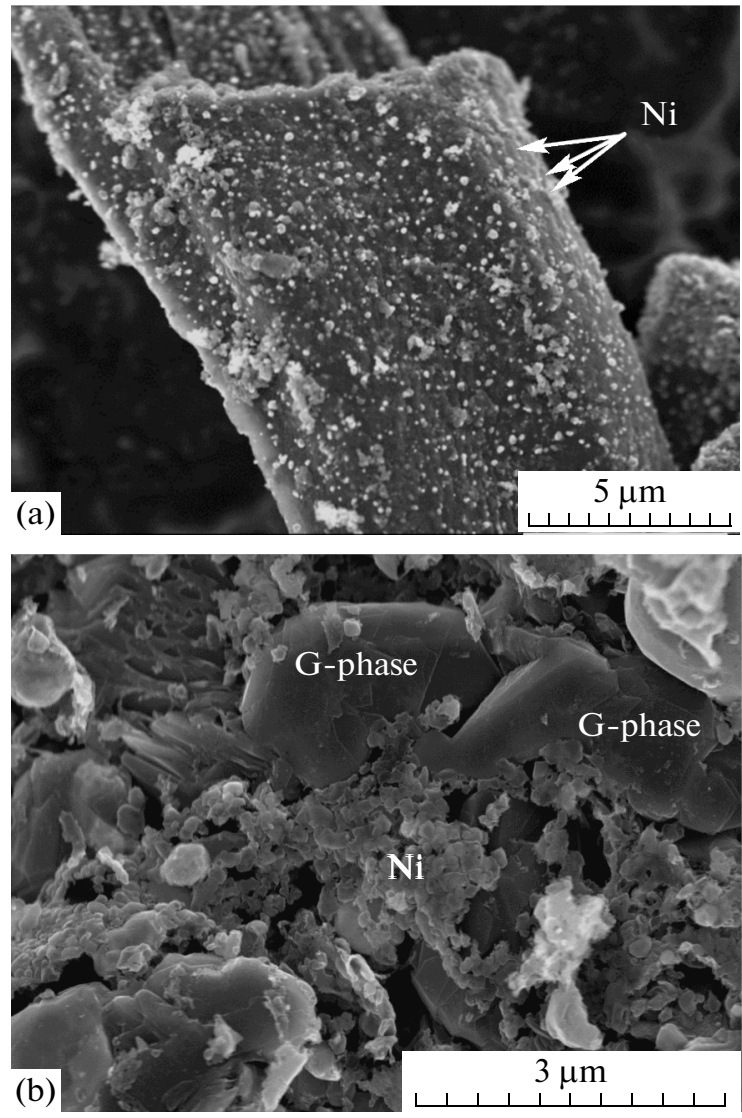

Fig. 2. Typical SEM microstructure images of the samples carbonized at $T_{\text {carb }}=$ (a) 1000 and (b) $1600^{\circ} \mathrm{C}$ in the presence of Ni catalyst. $G$ is the graphite phase, $\mathrm{Ni}$ are nickel catalyst particles. Arrows indicate the Ni-phase around which graphite phase nucleates at $T_{\text {carb }}=1000^{\circ} \mathrm{C}$.

this case, we note that the measured (effective) values of $E$ and $\delta$ were determined proceeding from the total sample cross section, rather than that of the composing biocarbon material. For comparison, there are also shown the dependences $E\left(T_{\text {carb }}\right)$ and $\delta\left(T_{\text {carb }}\right)$ we previously obtained in [15] for beech biocarbon matrices carbonized under the same conditions, but without catalyst, which can be conditionally divided into two linear ranges: as $T_{\text {carb }}$ is increased to $\sim 1000^{\circ} \mathrm{C}, E$ rapidly increases, while $\delta$ decreases; at $T_{\text {carb }}>1000^{\circ} \mathrm{C}$, these variations become significantly slower (Figs. 3a and $3 \mathrm{~b}$, curves 2 ). The rapid variations of $E$ and $\delta$ with temperature in the range $T_{\text {carb }}<1000^{\circ} \mathrm{C}$ are associated with the increase in the nanocrystalline phase fraction in the amorphous matrix; at $T_{\text {carb }}>1000^{\circ} \mathrm{C}$, elastic properties are controlled by the almost formed nanocrystalline phase [15]. In the same temperature range $T_{\text {carb }}=900-1000^{\circ} \mathrm{C}$, the insulator-strongly disordered metal transition known from [17, 18] is observed; furthermore, the behavior of thermal properties also changes [19-21]. For the bioC(Ni) sample series, the dependences $E\left(T_{\text {carb }}\right)$ and $\delta\left(T_{\text {carb }}\right)$ can be 
conditionally divided into three regions: $E$ increases and $\delta$ decreases in the ranges $T_{\text {carb }}<1000^{\circ} \mathrm{C}$ and $T_{\text {carb }}$ $>1300^{\circ} \mathrm{C}$; in the range $1000<T_{\text {carb }}<1300^{\circ} \mathrm{C}, E$ abruptly decreases while $\delta$ increases. In fact, in the range $850<T_{\text {carb }}<1000^{\circ} \mathrm{C}$, the dependences $E\left(T_{\text {carb }}\right)$ and $\delta\left(T_{\text {carb }}\right)$ for BE-C $(\mathrm{Ni})$ and BE-C samples are similar. To all appearance, the graphite phase ( $G$-phase) is still formed very slowly in this range, which is suggested by the data of X-ray and microstructural studies (see Subsection 3.1); the increase in $E$ and decrease in $\delta$ with $T_{\text {carb }}$ are controlled for BE-C(Ni) samples, as for BE-C, by the growing nanocrystalline phase and amorphous matrix. According to the structural studies, the $G$-phase rapidly grows in the region $T_{\text {carb }}>1300^{\circ} \mathrm{C}$, which does control the strong increase in $E$ and the decrease in $\delta$ with $T_{\text {carb }}$. It seems interesting that, despite the $G$-phase formation, an abrupt decrease in $E$ from 8.8 to $2.8 \mathrm{GPa}$ and an increase in the decrement from $4 \times 10^{-3}$ to $8 \times 10^{-3}$ is observed in the range $1000<$ $T_{\text {carb }}<1300^{\circ} \mathrm{C}$. Such low $E$ and high $\delta$ can be explained assuming that the $G$-phase formation prevents the nanocrystalline phase formation, which seems reasonable, since the crystallization processes of nanocrystalline and graphite phases seem to be competing. Then the formed graphite globules "float" in the amorphous matrix at $T_{\text {carb }} \sim 1300^{\circ} \mathrm{C}$, their fraction is small, which does cause the low value of $E$ mainly controlled by the amorphous phase. Then in the region $T_{\text {carb }}>1400^{\circ} \mathrm{C}, E$ increases due to a rapid increase in the $G$-phase fraction in the amorphous matrix. The increase in the elastic modulus with the carbonization temperature in the region $T_{\text {carb }}>1300^{\circ} \mathrm{C}$ is certainly related to the degree of biocarbon crystallization. It follows from the microscopy data (Fig. 2b) that, although a large number of graphite globules are formed at $T_{\text {carb }}=1600^{\circ} \mathrm{C}$, the amorphous (or quasi-amorphous) phase fraction still occupies a significant sample volume. It is possible that the fact that the Young's modulus for bioC$1600(\mathrm{Ni})$ samples does not reach the value of $E$ at $T_{\text {carb }}$ $=1000^{\circ} \mathrm{C}$ for both systems of BE-C and BE-C(Ni) samples indirectly argues in favor of our assumption that the nucleating graphite phase suppresses the nanocrystalline phase formation.

It seems interesting to compare the amplitude dependences of the Young's modulus and decrement for partially graphitized BE-C(Ni) samples with $T_{\text {carb }}$ from different temperature ranges: $1000<T_{\text {carb }}<$ $1300^{\circ} \mathrm{C}$ and $T_{\text {carb }}>1300^{\circ} \mathrm{C}$. Figures 4 and 5 show the dependences $E(\varepsilon)$ and $\delta(\varepsilon)$ for BE-C-1150(Ni) and BE-C-1400(Ni) samples, respectively. In the dependences $E(\varepsilon)$ and $\delta(\varepsilon)$ for BE-C-1400(Ni) (Fig. 5), as for BE-C-1500(Ni) and BE-C-1600(Ni), the following characteristic features may be noted. The modulus gradually decreases with increasing vibration amplitude. As for the decrement, in BE-C(Ni) samples with $T_{\text {carb }}>1300^{\circ} \mathrm{C}$, it remains almost unchanged with amplitude, but increases as large amplitudes are
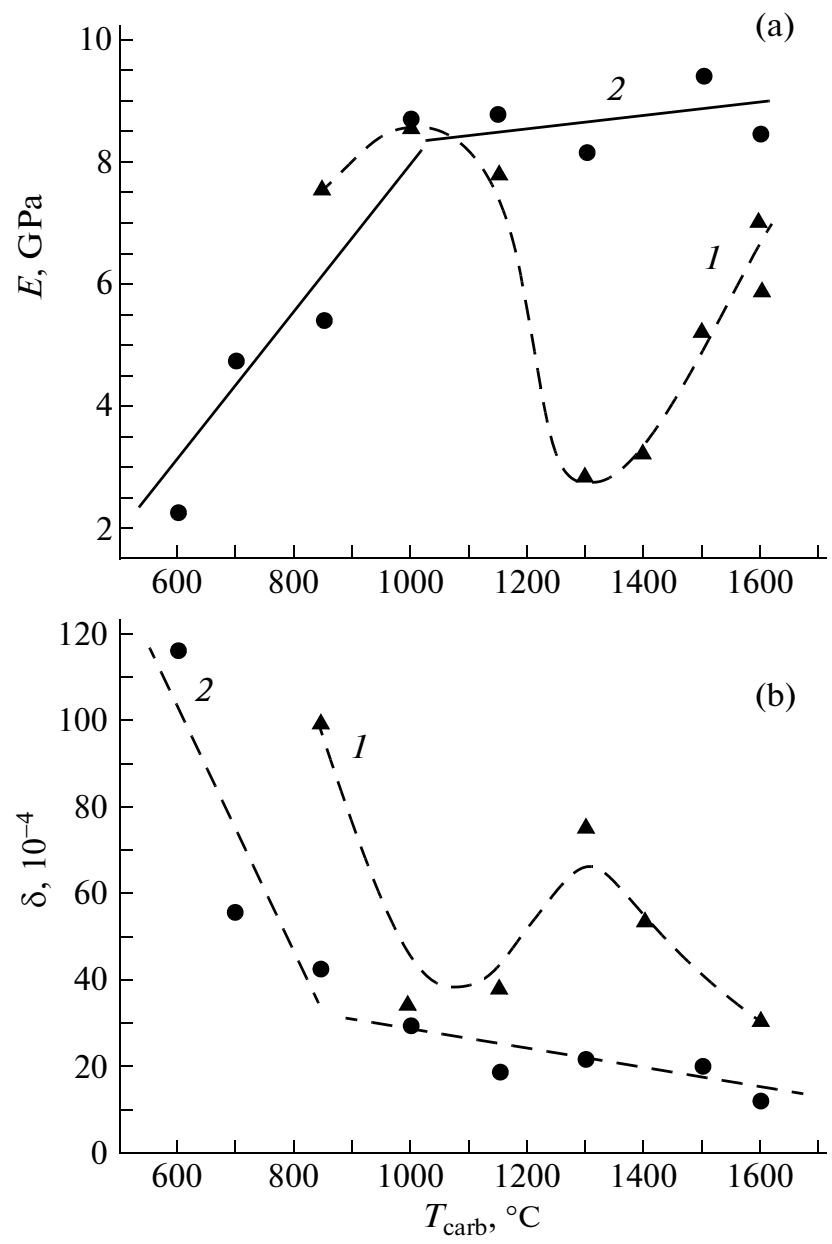

Fig. 3. Dependences of the (a) Young's modulus $E$ and (b) decrement $\delta$ of biomorphic carbon samples on their carbonization temperature $T_{\text {carb }}$ (1) BE-C(Ni) sample series (present study) and (2) BE-C sample series [15].

reached, $\varepsilon>10^{-4}$ (Fig. 5b). For BE-C(Ni) samples with $T_{\text {carb }}<1300^{\circ} \mathrm{C}$, the decrement does not increase even upon reaching maximum amplitudes used in this study (Fig. 4b). This indicates a decreased plasticity of samples with $T_{\text {carb }}<1300^{\circ} \mathrm{C}$. It should be noted that the plasticity effect (a decrease in $E$ and an increase in $\delta$ with $\varepsilon)$ manifests itself in $\mathrm{BE}-\mathrm{C}(\mathrm{Ni})$ beginning with $T_{\text {carb }}>1300^{\circ} \mathrm{C}$ when an already significant graphite phase volume is probably formed, graphite globules reach micrometer sizes, and the $G$-phase controls the behavior of elastic and inelastic properties of a material. It seems that dislocation glide providing plastic flow can be easier implemented in the crystal structure (even if it represents a set of graphite globules with sizes from fractions of micrometer to several micrometers), than in the amorphous structure. In the study of elastic and inelastic properties of pine biocarbon with $T_{\text {carb }}=1000$ and $2400^{\circ} \mathrm{C}$, it was shown that the crystallite size approximately twofold increases with increasing $T_{\text {carb}}$, which leads to a decrease in the 


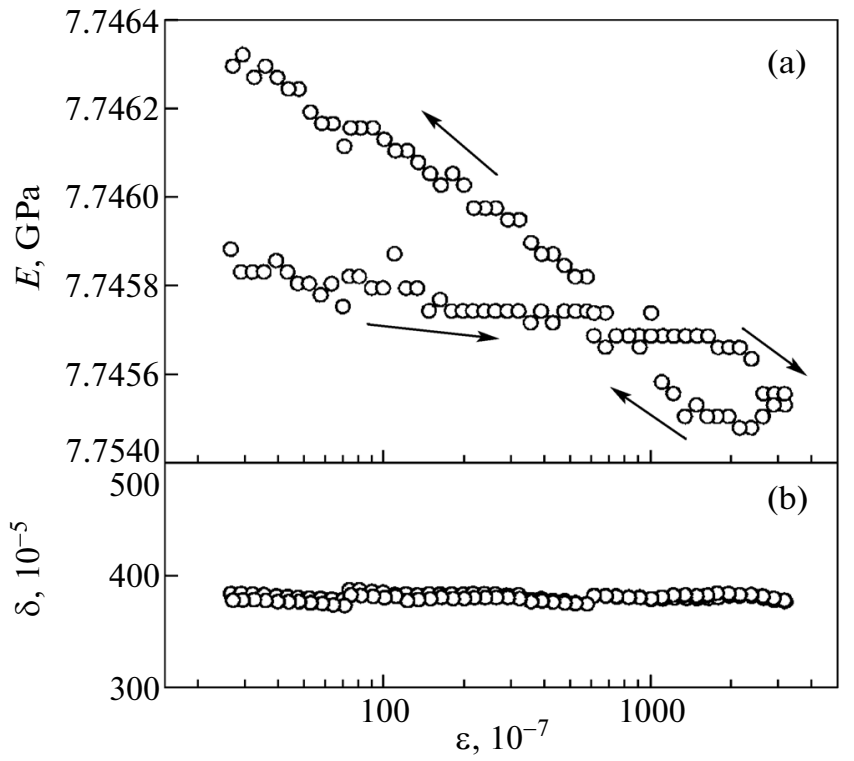

Fig. 4. Amplitude dependences of the (a) Young's modulus $E$ and (b) decrement $\delta$ for $\mathrm{BE}-\mathrm{C}(\mathrm{Ni})$ samples produced at $T_{\text {carb }}=1150^{\circ} \mathrm{C}$ in the presence of Ni catalyst. Measurements were performed in vacuum on samples subjected to high amplitudes at room temperature. Arrows indicate the $\varepsilon$ variation direction.

conditional yield stress, i.e., microplastic deformation facilitation [22]. In beech biocarbon carbonized without Ni catalyst, the plasticity effect (a decrease in $E$ and an increase in $\delta$ with $\varepsilon$ ) appeared even at $T_{\text {carb }} \geq$ $1000^{\circ} \mathrm{C}$, which was associated with nanocrystalline phase formation [15]. The absence of an increase in the microplasticity in BE-C(Ni) samples with $1000<$ $T_{\text {carb }}<1300^{\circ} \mathrm{C}$ even at large acoustic vibration amplitudes (in contrast to BE-C samples), as noted above, indirectly argues in favor of our assumption about the suppression of nanocrystalline phase formation during active nucleation of the graphite phase.

Thus, the biocarbon BE-C matrices with $T_{\text {carb }} \geq$ $1300^{\circ} \mathrm{C}$, studied in the present work, exhibit microplastic properties. Figure 6 shows the stress-microplastic strain diagrams obtained by the results of acoustic measurements in vacuum for the $\mathrm{BE}-\mathrm{C}(\mathrm{Ni})$ system samples. The diagrams were constructed using the dependences $E(\varepsilon)$ similar to the curves in Figs. 4 and 5, obtained with increasing amplitudes. The construction procedure for such diagrams is given in [23].

When comparing the curves $\sigma\left(\varepsilon_{d}\right)$ shown in Fig. 6, we can see that BE-C(Ni) samples with $T_{\text {carb }} \geq 1300^{\circ} \mathrm{C}$ have lower values of the conditional microyield stress $\sigma_{y}$ (the stress at $\varepsilon_{d}=1.0 \times 10^{-8}$ ), which is obviously associated with a significant increase in the volume fraction of the graphite phase and the formation of micrometer graphite globules. It should be noted that the BE-C samples prepared by beech carbonization at similar carbonization temperatures, but in the absence

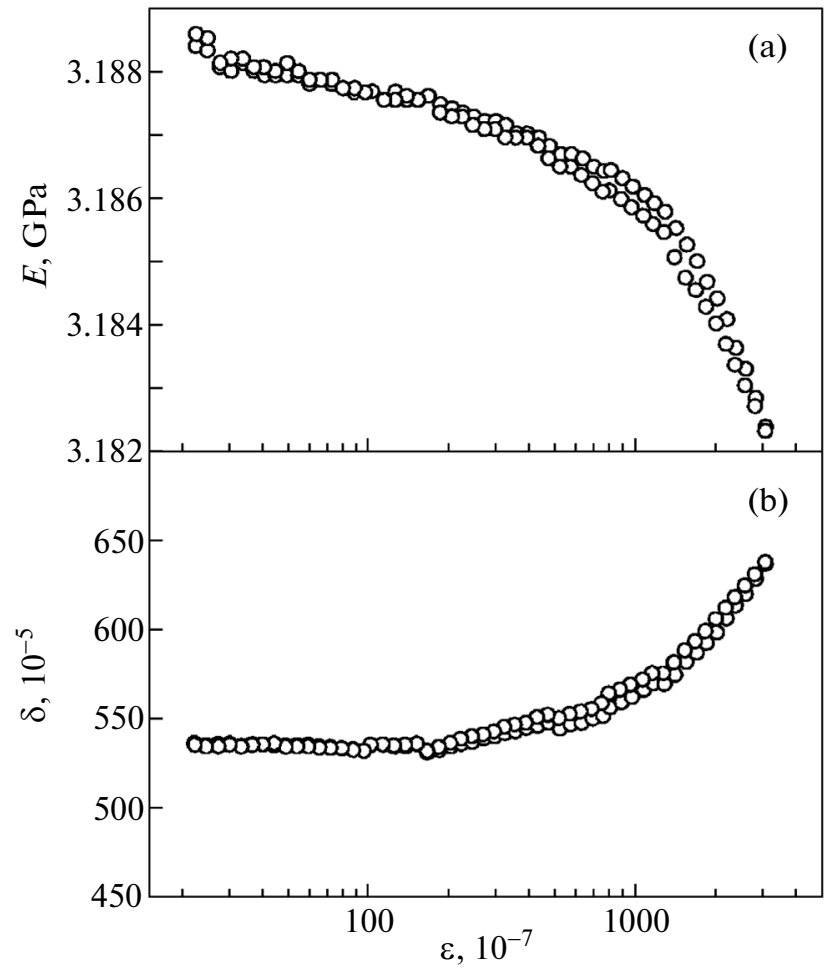

Fig. 5. Amplitude dependences of the (a) Young's modulus $E$ and (b) decrement $\delta$ for $\mathrm{BE}-\mathrm{C}(\mathrm{Ni})$ samples produced at $T_{\text {carb }}=1400^{\circ} \mathrm{C}$ in the presence of Ni catalyst. Measurements were performed in vacuum on samples subjected to high amplitudes at room temperature.

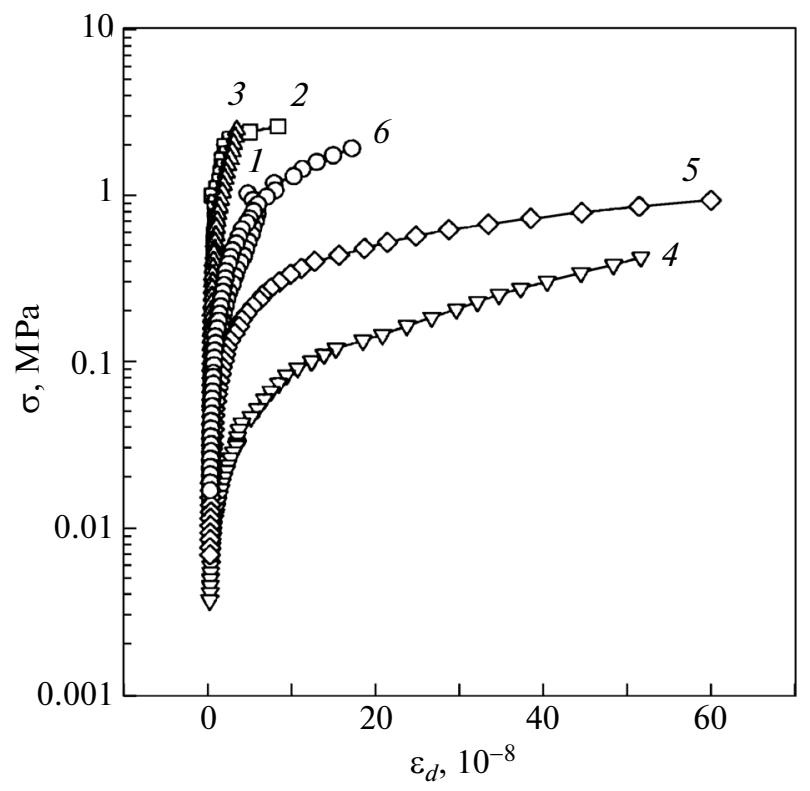

Fig. 6. Stress-microplastic strain curves obtained by the data of acoustic measurements in vacuum on $\mathrm{BE}-\mathrm{C}(\mathrm{Ni})$ samples carbonized in the presence of Ni catalyst. $T_{\text {carb }}=$ (1) 850 , (2) 1000, (3) 1150, (4) 1300, (5) 1400, and (6) $1600^{\circ} \mathrm{C}$. 
of Ni-containing catalyst, did not exhibit similar microplastic flow [15]. Thus, porous $\mathrm{BE}-\mathrm{C}(\mathrm{Ni})$ biocarbon matrices with $T_{\text {carb }}=1000$ and $1600^{\circ} \mathrm{C}$ show the highest Young's moduli; however, the samples with $T_{\text {carb }}=1600^{\circ} \mathrm{C}$ exhibit a significantly higher susceptibility to plastic flow.

\section{CONCLUSIONS}

The amplitude dependences of the Young's modulus $E$ and ultrasonic vibration decrement $\delta$ were determined for the first time for partially graphitized porous biocarbon matrices produced by beech wood carbonization at different temperatures $T_{\text {carb }}$ in the presence of nickel-containing catalyst.

The X-ray diffraction and electron microscopy investigations showed that the presence of a $\mathrm{Ni}$ catalyst during the carbonization results in a partial graphitization of biocarbons at $T_{\text {carb }} \geq 1000^{\circ} \mathrm{C}$. In this case, the graphite phase is formed as globules whose size increases from $50-100 \mathrm{~nm}$ at $T_{\text {carb }}=1000^{\circ} \mathrm{C}$ to $0.5-$ $3.0 \mu \mathrm{m}$ at $T_{\text {carb }}=1600^{\circ} \mathrm{C}$. The total volume fraction of the graphite phase also increases with an increase in $T_{\text {carb }}$. The measured dependences $E\left(T_{\text {carb }}\right)$ and $\delta\left(T_{\text {carb }}\right)$ contain three characteristic ranges of variations in the Young's modulus and logarithmic decrement with a change in the carbonization temperature. The observed behavior of the dependences $E\left(T_{\text {carb }}\right)$ and $\delta\left(T_{\text {carb }}\right)$ for biocarbons carbonized in the presence of nickel correlates with the evolution of their microstructure: $E$ increases while $\delta$ decreases with an increase in $T_{\text {carb }}$ in the ranges $T_{\text {carb }}<1000^{\circ} \mathrm{C}$ and $T_{\text {carb }}>$ $1300^{\circ} \mathrm{C}$, which is associated with the formation of nanocrystalline and graphite phases in the amorphous matrix in the former and latter cases, respectively. In the range $1000<T_{\text {carb }}<1300^{\circ} \mathrm{C}, E$ abruptly decreases and $\delta$ increases, which most probably indicates the suppression of the formation of a nanocrystalline phase by the formed graphite phase. In the range $T_{\text {carb }} \geq$ $1300^{\circ} \mathrm{C}$, it was found that the microplastic deformation is facilitated (the conditional yield stress $\sigma_{y}$ decreases). The largest values of $E$ were obtained for samples with $T_{\text {carb }}=1000$ and $1600^{\circ} \mathrm{C}$. However, the samples with $T_{\text {carb }}=1600^{\circ} \mathrm{C}$ showed a higher susceptibility to microplastic deformation, which is caused by a significantly larger volume fraction of the graphite phase.

\section{ACKNOWLEDGMENTS}

This study was supported in part by the Russian Foundation for Basic Research (project no. 14-0300496), the Presidium of the Russian Academy of Sciences (program no. P-20), and the Junta de Andalucia, Spain (grant no. P09-TEP-5152).

\section{REFERENCES}

1. C. E. Byrne and D. C. Nagle, Carbon 35 (2), 267 (1997).
2. P. Greil, T. Lifka, and A. Kaindl, J. Eur. Ceram. Soc. 18, 1961 (1998).

3. A. R. de Arellano-Lopez, J. Martinez-Fernandez, P. Gonzalez, C. Domínguez, V. Fernandez-Quero, and M. Singh, Int. J. Appl. Ceram. Technol. 1 (1), 56 (2004).

4. A. G. Pandolfo and A. F. Hollenkamp, J. Power Sources 157, 11 (2006).

5. L. Zhang and X. S. Zhao, Chem. Soc. Rev. 38, 2520 (2009).

6. M. T. Johnson and K. T. Faber, J. Mater. Res. 26 (1), 18 (2011).

7. M. T. Johnson, A. S. Childers, J. Ramírez-Rico, H. Wang, and K. T. Faber, Composites, Part A 53, 182 (2013).

8. A. Gutiérrez-Pardo, J. Ramírez-Rico, A. R. de Arellano-López, and J. Martínez-Fernández, J. Mater. Sci. 49 (22), 7688 (2014).

9. H. M. Cheng, H. Endo, T. Okabe, K. Saito, and G. B. Zheng, J. Porous Mater. 6 (3), 233 (1999).

10. A. Oya and H. Marsh, J. Mater. Sci. 17 (2), 309 (1982).

11. R. Sinclair, T. Itoh, and R. Chin, Microsc. Microanal. 8 (4), 288 (2002).

12. M. Sevilla, C. Sanchís, T. Valdés-Solís, E. Morallón, and A. B. Fuertes, J. Phys. Chem. C 111 (27), 9749 (2007).

13. F. J. Derbyshire, A. E. B. Presland, and D. L. Trimm, Carbon 13 (2), 111 (1975).

14. C. Yokokawa, K. Hosokawa, and Y. Takegami, Carbon 5 (5), 475 (1967).

15. B. K. Kardashev, T. S. Orlova, B. I. Smirnov, A. Gutierrez, and J. Ramirez-Rico, Phys. Solid State 55 (9), 1884 (2013).

16. S. P. Nikanorov and B. K. Kardashev, Elasticity and Dislocation Inelasticity of Crystals (Nauka, Moscow, 1985) [in Russian].

17. V. V. Popov, T. S. Orlova, E. Enrique Magarino, M. A. Bautista, and J. Martínez-Fernandez, Phys. Solid State 53 (2), 276 (2011).

18. V. V. Popov, T. S. Orlova, and J. Ramirez-Rico, Phys. Solid State 51 (11), 2247 (2009).

19. I. A. Smirnov, B. I. Smirnov, T. S. Orlova, Cz. Sulkovski, H. Misiorek, A. Jezowski, and J. Muha, Phys. Solid State 53 (11), 2244 (2011).

20. L. S. Parfen'eva, T. S. Orlova, N. F. Kartenko, B. I. Smirnov, I. A. Smirnov, H. Misiorek, A. Jezowski, J. Muha, and M. C. Vera, Phys. Solid State 53 (11), $2398(2011)$.

21. N. F. Kartenko, T. S. Orlova, L. S. Parfen'eva, B. I. Smirnov, and I. A. Smirnov, Phys. Solid State $\mathbf{5 6}$ (11), 2348 (2014).

22. B. K. Kardashev, T. S. Orlova, B. I. Smirnov, T. E. Wilkes, and K. T. Faber, Phys. Solid State 51 (12), 2463 (2009).

23. B. I. Smirnov, Yu. A. Burenkov, B. K. Kardashev, D. Singh, K. C. Goretta, and A. R. de Arellano-Lopez, Phys. Solid State 43 (11), 2094 (2001).

Translated by A. Kazantsev 